\title{
A LEI DO FEMINICÍDIO E A PROMESSA DE REDUÇÃO DA VIOLÊNCIA LETAL CONTRA A MULHER: O CAMINHO DO RECONHECIMENTO DO DIREITO DA MULHER
}

\author{
Marcus Vinícius Santana Teles ${ }^{1}$
}

\begin{abstract}
Resumo: Este texto tem por objetivo analisar a violência letal contra a mulher, as alterações legislativas promovidas pela Lei 13.104/2015, responsável pela tipificação do homicídio contra mulheres em condição de violência de doméstica e/ou menosprezo à condição de mulher e a transfiguração desse delito em crime hediondo. Com foco na motivação do legislador em tipificar a referida violência, nos principais eventos, normas e julgados no âmbito do direito internacional e dos direitos humanos. Destacando o histórico da violência contra mulher, a necessidade, e principalmente o surgimento das de uma política pública priorizando a redução da violência contra a mulher e, principalmente da violência letal. Demonstrando que mesmo tendo valor essencialmente simbólico, não há (veria) outra política a ser adotada pelo Estado brasileiro, devido a complexidade do problema e das pressões internacionais.
\end{abstract}

Palavras-chave: Violência doméstica, Feminicídio, Direitos Humanos, Direito Internacional.

Resumen: Este texto tiene por objetivo analizar la violencia letal contra la mujer, las alteraciones legislativas promovidas por la Ley 13.104 / 2015, responsable por la tipificación del homicidio contra mujeres en condición de violencia de hogar y/o menosprecio a la condición de mujer y la transfiguración de ese delito en crimen

1 Graduado em Direito pela Universidade Federal de Goiás. É advogado e servidor da UEG, atuando como assessor de convênios gerais. Tem interesse por temas jurídicos, em especial Direitos Humanos, Direito Constitucional, Teoria do Estado e Filosofia do Direito.

E-mail: mv.santanateles@gmail.com. 
atroz. Con el foco en la motivación del legislador en tipificar dicha violencia, en los principales eventos, normas y juzgados en el ámbito del derecho internacional y de los derechos humanos. Destacando el histórico de la violencia contra la mujer, la necesidad, y principalmente el surgimiento de una política pública priorizando la reducción de la violencia contra la mujer y, principalmente, de la violencia letal. Demostrando que aun teniendo valor esencialmente simbólico, no hay (vería) otra política a ser adoptada por el Estado brasileño, debido a la complejidad del problema $\mathrm{y}$ de las presiones internacionales.

Palabras clave: Violencia doméstica, Feminicidio, Derechos humanos, Derecho internacional.

Abstract: The purpose of this text is to analyze the lethal violence against women, the legislative changes promoted by Law 13.104/2015, responsible for typifying homicide against women in domestic violence and / or disregard for women's condition and the transfiguration of this crime in Heinous crime. Focusing on the motivation of the legislator to typify this violence, in the main events, norms and judgments in the scope of international law and human rights. Emphasizing the history of violence against women, the need, and especially the emergence of a public policy prioritizing the reduction of violence against women, and especially of lethal violence. Demonstrating that, despite having an essentially symbolic value, there is no other policy to be adopted by the Brazilian State, due to the complexity of the problem and international pressures.

Keywords: Domestic Violence, Feminicide, Human Rights, International Law.

\section{CONSIDERAÇÕES INICIAIS}

Em 09 de março de 2015 foi sancionada pela Presidenta da República a Lei $\mathrm{n}^{\circ} 13.104 / 2015$, decretada pelo Congresso Nacional. Incluindo mais uma qualificadora do crime de homicídio no rol previsto no Código Penal (art. $121, \$ 2^{\circ}$ e seus incisos subsequentes) e que também foi abarcada pela Lei dos Crimes Hediondos (Lei no 8.072/1995). A competência para julgamento deste delito será do Tribunal do Júri, por se tratar de crime doloso contra a vida. Nesse sentido aquele que vier a atentar contra a vida de uma mulher num contexto de "violência doméstica e familiar" ou por "menosprezo ou discriminação à sua condição", terá a pena aumentada de 12 (doze) a 30 (trinta) anos de prisão. 
Antes desta alteração, não havia nenhuma punição especial pelo fato de o homicídio ser praticado contra a mulher por razões da condição de sexo feminino ou por condições de gênero. $O$ feminicídio era punido, de forma genérica, como sendo homicídio (art. 121 do Código Penal). A depender do caso concreto, o feminicídio (mesmo sem ter ainda este nome) poderia ser enquadrado na forma qualificada por motivo torpe (inciso I do $\$ 2^{\circ}$ do art. 121) ou fútil (inciso II do $\$ 2^{\circ}$ do art. 121) ou, ainda, pelo fato da dificuldade da vítima de se defender (inciso IV, também do Código Penal).

Conforme assevera Aline PASSOS "Do ponto de vista da imputação, a nova lei não conduz a qualquer alteração relevante, posto que seu objeto, em tese, já cabia na definição ampla e vaga da qualificadora do homicídio por "motivo torpe"" (2015, p. 70). Enquanto que outros consideram essa política afirmativa legislativa um avanço na mudança de perspectiva em relação à violência contra a mulher. Enquanto outros, consideram um avanço pois, reconhece a existência da violência contra a mulher e reconhece o direito da mulher como um direito humano (OCÁRIZ, 2016).

De acordo com o relatório final da CPMI da Violência Contra a Mulher de 2012, feminicídio compreendem-se os homicídios de mulheres pelas condições de serem mulheres. Um crime que é justificado sócio culturalmente por uma história de dominação da mulher pelo homem onde a indiferença, quando, não muito, incentiva da sociedade machista traz uma espécie de estímulo. A desigualdade de gênero coloca as mulheres em uma condição hierarquicamente inferior aos homens, materializando-se por meio de crimes, espancamentos, palavras cruéis e assassinatos.

É, portanto, clara a manifestação de valores sexistas, fruto das relações de poder entre os gêneros perpetuados na cultura do país. Sob distintos contextos, ao longo da história, mulheres são assassinadas pelo tão só fato de possuírem este gênero. $O$ fenômeno é parte contínua desta violência também expressada em estupros, torturas, mutilações genitais, infanticídios, violência sexual nos conflitos armados, exploração e escravidão sexual, incesto e abuso sexual dentro e fora da família, dentre outras diversas formas (BIANCHINI; MARINELA; MEDEIROS, 2015).

Sabemos que a tutela do sistema penal também se revela extremamente problemática para as vítimas abarcadas pela Lei do Feminicídio, as quais constantemente sofrem da violência. $\mathrm{O}$ sistema punitivo estatal mostra-se uma falsa promessa na busca pela efetivação da igualdade de gênero, pois é 
insuficiente na proteção das mulheres, bem como na consolidação de seus direitos. Conforme GOMES (2015, p. 191),

Trata-se, especialmente, de um diálogo entre o feminismo e o direito penal e a tentativa de garantir a efetivação dos direitos humanos das mulheres por meio de um sistema que já provou ser também violador desses mesmos direitos

Entretanto, não há como negar a relevância da Lei 13.104/2015, pois,

A judicialização do feminicídio é uma das vertentes do debate sobre o problema, ela expressa um tipo de resposta possível no enfrentamento do fenômeno, sem significar a totalidade desta discussão, mas é também, elemento fundamental para avançar neste largo e arenoso caminho, que compreende o enfrentamento da expressão letal da violência de gênero praticada contra as mulheres (GOMES, 2015, p. 192)

A luta das mulheres pela igualdade de gênero nunca poderá ser minimizada em aspectos homogêneos, tendo em vista se tratar de um movimento plural, cujas diversas facetas abordam as inúmeras nuances da misoginia. Seja nos aspectos microfísicos, nas sutis discriminações cotidianas que foram enraizadas pelos costumes sociais e disseminadas por instituições tradicionais, seja em um viés amplo de violência psíquica, física e sexual, todas contribuindo com o controle do ser feminino pelo machismo.

Se de um lado, demandam a necessidade de uma ampla revisão dos tipos penais existentes, defendendo a descriminalização de condutas hoje tipificadas como crime (aborto, posse sexual mediante fraude, sedução, casa de prostituição e adultério, entre outras), e a redefinição de alguns crimes, especialmente o estupro, propondo o deslocamento do bem jurídico protegido (que o estupro seja deslocado de 'crime contra o costume' como o é hoje para 'crime contra a pessoa') com vistas a excluir seu caráter sexista. De outro lado, demanda o agravamento de penas no caso de assassinato de mulheres e a criminalização de condutas até então não criminalizadas, particularmente a violência doméstica e o assédio sexual (ANDRADE, 2003).

Portanto, por causa da multiplicidade abrangida pelo feminismo, é necessário um recorte meramente metodológico acerca da análise do presente texto com foco na violência contra a mulher, cujo ápice dessa violência é representado, justamente, pelo denominado feminicídio.

Primeiramente será realizada uma análise da violência e da violência contra a mulher no passado e contemporaneamente. Será feito um esboço 
histórico explicitando a origem da tutela especial para as mulheres no direito internacional e nos direitos humanos. Por sua vez a origem do termo feminicídio e quais os motivos levaram a Corte Interamericana de Direitos Humanos a exigir, por parte dos Estados membros uma política de defesa da mulher. Além do detalhamento da Lei 13.104/15 e as considerações finais.

\section{VIOLÊNCIA}

A violência contra a mulher não é um fato novo. Novidade é a preocupação com a superação dessa violência como condição necessária para a construção de uma humanidade melhor. No Brasil percebemos a judicialização e a criminalização da violência contra a mulher a partir da lei 11.343/2006, onde vemos a criação e a consolidação de estruturas específicas a fim de proteger as vítimas dessa violência, mediante a atuação do aparelho policial e/ou jurídico na punição dos agressores.

Poderíamos dizer que a violência é uma constante na natureza humana, desde o aparecimento do homem no mundo até o surgimento da civilização, a violência nos acompanha a todo o momento, em nosso cotidiano, em nossa condição tão selvagem quanto humana. (PORTO, 2007). Desde os primórdios, as sociedades baseavam sua sobrevivência através da força física. Em tempos de guerra a economia baseava-se em saques. A caça, a pesca, agricultura ou até a extração de recursos minerais, são atividades compatíveis com a força corporal, atributo masculino.

A mulher tinha a função doméstica, a geração e a criação dos filhos, não tinham força bruta necessária para a proteção do grupo, por isso eram consideradas menos importantes. A partir daí estava moldada o arquétipo do macho protetor e provedor, com poderes supremos, valores aproximados da sociedade patriarcal.

A violência é um fenômeno complexo, com vários fatores determinantes, como, biológicos, sociais, culturais, econômicos e políticos. A definição é complexa e se baseia na apreciação de tais fatos a uma determinada sociedade, ou seja, valores podem ser aceitáveis ou inaceitáveis a depender de cada sociedade. E da revisão de seus valores através do tempo. Homens e mulheres, ao longo da história da humanidade, desempenharam papéis sociais bem diferentes, a relação social entre homens e mulheres pode variar historicamente, 
de cultura para cultura, conforme convenções elaboradas socialmente. Nesse sentido Maria Berenice DIAS (2007, p. 15) leciona que,

Desde que o mundo é mundo humano, a mulher sempre foi discriminada, desprezada, humilhada, coisificada, objetificada, monetarizada. Ninguém duvida que a violência sofrida pela mulher não é exclusivamente de responsabilidade do agressor. A sociedade ainda cultiva valores que incentivam a violência, o que impõe a necessidade de se tomar consciência de que a culpa é de todos. O fundamento é cultural e decorre da desigualdade no exercício do poder e que leva a uma relação dominante e dominado. [...] ao homem sempre coube o espaço público e a mulher foi confinada nos limites da família e do lar, o que enseja a formação de dois mundos: um de dominação, externo, produtor; o outro de submissão, interno e reprodutor [...]. A sociedade outorga ao macho o papel paternalista, exigindo uma postura de submissão da fêmea. As mulheres acabam recebendo uma educação diferenciada, pois necessitam ser mais controladas, mais limitadas em suas aspirações e desejos (DIAS, 2007, p. 17).

Portanto a violência de gênero está relacionada a uma questão sociológica, onde papeis atribuídos a homens e mulheres se diferem. Onde um grupo tem mais poder que outro, por questão de gênero, questão histórica de determinação social dos papéis masculinos e femininos atribuídos pesos diferenciados, supervalorizando um e subvalorizando o outro (BIANCHINI, 2014).

No Brasil, desde o período colonial a mulher era reservada à vida doméstica, procriar e criar os filhos (COSTA; NUNES; AQUINO, 2012). Portanto, guardamos um histórico de violência e desigualdade, inclusive no mundo jurídico.

\section{Contextualizando}

É consenso entre a maioria dos antropólogos que o ser humano surgiu há mais de 2 milhões de anos, era nômade e sobrevivia do que coletava na natureza. Não havia necessidade de força física para sobreviver, e as mulheres possuíam lugar central.

A mulher era considerado um ser sagrado, pois dava a vida e ajudava na fertilidade da terra e dos animais, logo não havia desigualdade e a relação era de cooperação. Em algum momento do neolítico, o homem passa a dominar a função biológica e tem o poder de controlar a sexualidade da mulher.

Surge então o casamento, na fórmula de a mulher ser propriedade do homem e a transmissão da herança através da descendência masculina. Por volta de 10.000 a 8.000 a.C. o homem passa a fundir metais, consequentemente 
começa a produzir armas e instrumentos agrícolas. O ser humano deixa de ser nômade e começam a se formar as cidades, impérios, etc. Nesse período a sociedade se torna patriarcal, começa a reinar a lei do mais forte e a mulher então é reduzida ao âmbito doméstico.

Por volta de 2.000 a.C. existiam vários mitos da criação, sendo que alguns colocavam a mulher com função central. Aos poucos os diversos mitos da criação (sejam eles quais forem) foram dando espaço para mitos onde o deus macho cria o mundo a partir de si mesmo. Por exemplo, o mito hebraico-cristão, onde Javé é deus único, e dita as regras de comportamento, ao contrário dos mitos primitivos onde a grande mãe é permissiva e não coercitiva.

A relação homem-mulher-natureza passa a ser de dominação e a mulher é reconhecida pela submissão. No mito da criação judaico-cristão o conhecimento do bem e do mal vem de uma experiência completa da sexualidade, conhecimento este que, na cultura patriarcal é feminino por excelência. É preciso precaver-se de todas as maneiras contra a mulher, impedi-la de interferir nos processos decisórios, fazer com que ela introjete uma ideologia que a convença da própria inferioridade em relação ao homem.

No mito judaico-cristão, o criador masculino cria o homem e a partir dele cria a mulher. Percebe-se o deslocamento simbólico da mulher para a inferioridade. Na perspectiva de MURARO (2016), a grandeza pertence ao homem e a narrativa do livro de Gêneses serve para manter a mulher em seu devido lugar.

Se na Alta Idade Média as mulheres tem acesso às artes, às ciências, etc. A partir do séc. XIV até meados do século XVIII percebemos a repressão sistemática do feminino. Desde a antiguidade as mulheres (curadoras, parteiras...) detinham um saber próprio que era transmitido de geração em geração. A religião católica e posteriormente a protestante contribuíram de maneira decisiva para a centralização do poder/saber.

Através da Inquisição, torturavam e matavam aqueles que eram julgados heréticos ou bruxos. No período da Inquisição as mulheres são abertamente perseguidas, torturadas e mortas. Percebe-se que como estão mais ligadas à sexualidade, elas se tornam as 'agentes por excelência do demônio (a feiticeira). Desse modo as mulheres são reduzidas ao âmbito doméstico.

Sendo relevante destacar que também a mulher foi discriminada pela ciência. Gustave Le Bom, um dos fundadores da psicologia social, afirmou que uma mulher inteligente é raro, ao passo que Charles Darwin dizia que as mesmas possuíam características das raças inferiores (HERMANN, 2008). 
Posteriormente, houveram mudanças significativas, com o aumento da parcela da população de mulheres casadas que trabalhavam por salário, se em 1940, em 1980, eram mais da metade (HOBSBAWN, 2001). Apesar disso, as desigualdades sociais e culturais são fatores altamente relevantes na discriminação feminina, podemos citar, a diferença de salários, as posições que ocupam no trabalho, além do número de agressões e mortes envolvendo mulheres (MOREIRA; DE SOUZA; DE SOUZA, 2015).

Contemporaneamente poucas mulheres ocupam espaços de decisão na sociedade, e o papel de dona de casa é visto como uma obrigação, um espaço reservado unicamente para as mulheres. Ficam aprisionadas a antigos valores morais e ainda sofrem dentro e fora de casa.

Pesquisas recentes (a partir dos anos 2000) indicam que, "são rotineiros os casos de mutilação do corpo e marcas feitas com objetos cortantes, impressas principalmente nas partes que mais representam a sexualidade feminina" (GOMES, 2015, p. 196). Concluímos que a violência contra a mulher é resultado de uma cultura patriarcal, a violência de gênero é uma forma de controle do corpo feminino.

\section{Direitos humanos Das MUlHeRES}

Não há como falar sobre conquistas das mulheres sem antes falar sobre o fenômeno de mulheres que foram à luta reivindicando os direitos das mulheres. Nesse sentido podemos afirmar que, movimentos sociais de massa explicitamente femininos surgiram apenas a partir da década de 60 , originários dos movimentos sociais, tanto por seus participantes relativos aos direitos humanos, como por suas revolucionárias tendências a favor da contracultura. Esse arcabouço de organização, não apenas ideológica, como também prática, foi responsável pelas mais significativas mudanças já ocorridas, em benefício da nova formatação da mulher na sociedade, refletindo-se na atuação em diversos setores, entre eles o da economia e da política (MOREIRA ; DE SOUZA; DE SOUZA, 2015, p. 262).

Ante o exposto afirmamos também que, foi o feminismo que tornou as múltiplas formas de violência contra a mulher, um problema público. Denunciando e politizando desde a violência cotidiana até a violência física. De início, BORGES e GEBRIM (2014, p. 59-60) nos ensinam que, 
Embora a questão dos direitos humanos das mulheres e da igualdade de gênero venha recebendo atenção, no cenário internacional, desde a primeira metade do século vinte, até a década de setenta, com impulso maior nos anos noventa, as iniciativas adotadas nessa área caracterizavam-se pela adoção de instrumentos de direitos humanos de natureza genérica, que consagravam a proibição de discriminação por razão de sexo, junto ao direito de igualdade perante a lei, sem reconhecer as mulheres como um coletivo com necessidades especiais de proteção. [...] Sob o pretexto do tecnicismo e do caráter neutral do direito, a perspectiva de gênero encontrava-se ausente nas normas jurídicas internas dos países. Não havia o reconhecimento de que a violência contra as mulheres representa um grave problema de saúde pública e de violação aos direitos humanos, inexistindo respostas institucionais voltadas a reverter essa situação estrutural de discriminação.

O marco fundamental para o desenvolvimento dos direitos humanos foi a Declaração Universal dos Direitos do Homem, elaborada após o fim da $2^{\text {a }}$ Guerra Mundial, no ano de 1948. A grande maioria das nações concordou na elaboração de um documento e na preservação de direitos mínimos, básicos e fundamentais a qualquer pessoa. Sendo, obviamente o Brasil um de seus países signatários.

Já em 1951 a OIT (Organização Internacional de Trabalho) aprovou a Convenção $n^{\circ} 100$, posteriormente aprovada através do Decreto Legislativo $\mathrm{n}^{\circ} 24$, de 29 de maio de 1956 e ratificado através do Decreto $\mathrm{n}^{\circ} 41.721$, de 25 de junho de 1957, que dispunha sobre a igualdade de remuneração entre homens e mulheres. Delineando o caminho dos direitos das mulheres, que foi traçado através de inúmeros tratados e pactos internacionais que dispunham sobre direitos humanos.

No ano de 1975 foi realizada no México a I Conferência Mundial sobre a Mulher, onde foi elaborada a Convenção sobre a Eliminação de todas as formas de discriminação contra as mulheres. Por meio da Resolução 34/180, em 18 de dezembro de 1979 foi aprovada na Assembleia Geral das Nações Unidas. Sendo assinada com ressalvas pelo Brasil em 1981 e somente ratificada em 1984, entrando em vigor em 02/03/1984 e somente em 1994 o governo brasileiro retirou as reservas e ratificou plenamente a Convenção. Já nesta Convenção contém o dever do Brasil em promover a igualdade formal e material entre os gêneros, a fomentação da não discriminação da mulher e por fim prevê a adoção temporária de medidas afirmativas com fim da promoção da igualdade de gêneros (OCÁRIZ, Último acesso em: 17/01/2018).

Em 1993 foi realizada em Viena a Conferência Mundial de Direitos Humanos. Já em 1994 a Organização dos Estados Americanos - OEA - ampliou a 
proteção aos direitos das mulheres, editando a Convenção para Prevenir, Punir e Erradicar a Violência contra a Mulher - Convenção de Belém do Pará. Ratificando e ampliando o programa de ação da Conferência de Viena. Discorrendo sobre a referida convenção Graziele Carra Dias OCÁRIZ (p. 4) leciona que,

Entre as conquistas merece destaque a possibilidade de peticionar junto à Comissão Interamericana de Direitos Humanos. Disciplina diversos tipos de violência contra a mulher, no âmbito familiar, na comunidade e a perpetrada pelo Estado ou seus agentes. [...] Além do constrangimento do Estado, a Comissão Interamericana poderá condená-lo pela afronta a direitos fundamentais, assegurados às mulheres, determinando medidas cabíveis, como, por exemplo, fixação de indenização aos familiares da vítima.

Em 1995 foi realizada a IV Conferência Mundial da Mulher, realizada pelas Nações Unidas em Beijing na China. Onde foi aprovada uma plataforma de atuação em relação à violência doméstica. Destaca-se o artigo $7^{\circ}$ da Convenção de Belém do Pará que determinou aos Estados destinatários, inclusive ao Brasil a partir do Decreto $\mathrm{n}^{\circ} 1.973$ de $1^{\circ}$ de agosto de

1996. Na letra F: estabelecer procedimentos jurídicos justos e eficazes para a mulher sujeita de violência, inclusive entre outros, medidas de proteção, juízo oportuno e efetivo acesso a tais processos. Ainda na letra G esclarece que: estabelecer mecanismos judiciais e administrativos necessários para assegurar que a mulher sujeita a violência tenha efetivo acesso a restituição, reparação do dano e outros meios de compensação justos e eficazes.

O embaixador José Augusto Lindgren ALVES (2001, p. 240-241), expõe a importância da IV Conferência Mundial da Mulher na jornada traçada pelos direitos humanos da mulher, incorporando a perspectiva de gênero para compreender a posição da mulher na sociedade, segundo ele,

As conferências da ONU sobre a mulher, por sua vez, sempre tendo como subtítulo os termos, Igualdade, Desenvolvimento e Paz, foram expandindo os campos prioritários de atuação. A partir dos subtemas do trabalho, da educação e da saúde, na Conferência do México, em 1975, passaram a incluir a violência, conflitos armados, ajustes econômicos, poder de decisão e direitos humanos em Nairóbi, em 1985, e, agora, abrangem os novos temas globais do meio ambiente e dos meios de comunicação, além da situação particular das meninas. As estratégias, que privilegiavam originalmente a integração da mulher no processo de desenvolvimento, em Nairóbi, já afirmavam que, o papel da mulher no processo de desenvolvimento tem relação com o desenvolvimento de toda a sociedade. Faziam-no, porém, sem um exame mais detido das relações históricas assimétricas homem-mulher, que incorporam relações de poder. 
Em Beijing, as relações de gênero, com seu substrato de poder, passaram a constituir o cerne das preocupações e dos documentos adotados, tendo como asserção fundamental a reafirmação dos direitos da mulher como direitos humanos. E nestes se acham, hoje, naturalmente, incluídos seus direitos e necessidades específicos, particularmente os reprodutivos, os sexuais e os referentes à violência e que são vítimas, por indivíduos e sociedades, tradições, legislações e crenças.

Num primeiro movimento houve a descriminalização de alguns delitos, com vistas a corrigir a institucionalização da discriminação. Posteriormente foram editadas leis objetivando coibir a violência dentro da família e regulamentada a atuação do Estado na prevenção (FRÍES; HURTADO apud BORGES; GEBRIM, 2014).

É interessante notar que a legislação brasileira apresenta histórico negativo, no que tange à questão de gênero, temos exemplos de textos legais que previam tratamento discriminatório em relação a mulher, conforme assevera BIANCHINI (2014, p. 21),

São exemplos o Código civil de 1916 (e que vigorou até 2002), que previa, em seu art. 219 , inciso IV, a possibilidade de o marido anular o casamento caso constatasse que sua esposa fora deflorada anteriormente (inexistindo qualquer previsão análoga para a mulher que descobrisse que seu marido mantivera relações sexuais antes do casamento) [...]. (BIANCHINI, p. 21, grifado no original).

O problema dos assassinatos de mulheres, relacionados com violência de gênero, os denominados feminicídios, ganhou visibilidade nos países latino-americanos nos anos 90. Gradativamente os governos locais foram dando respostas, e lentamente os casos passaram a ser oficialmente reconhecidos como feminicídios.

Vale destacar a ementa e o artigo $1^{\circ}$ da lei $11.340 / 2006$, que funciona como divisor de águas na luta contra a violência contra a mulher. Criando, "mecanismos para coibir e prevenir a violência doméstica e familiar contra a mulher [...] e estabelece medidas de assistência e proteção às mulheres em situação de violência doméstica e familiar." (BRASIL, 2006).

\section{O FEMICÍDIO/FEMINICÍDIO}

Segundo (BORGES; GEBRIM, 2014), o termo femicide foi utilizado pela primeira vez no Tribunal Internacional de Crimes contra Mulheres, em 
Bruxelas, no ano de 1976, para caracterizar o assassinato de mulheres pelo fato de serem mulheres. No entanto, não foi dado um conceito sobre o tema, o que veio a ser feito posteriormente em 1990 por Russel e Caputi, quando definiram femicide como "o assassinato de mulheres realizado por homens motivado por ódio, desprezo, prazer ou um sentido de propriedade sobre as mulheres" (CAPUTI; RUSSEL apud BORGES; GEBRIM, 2014, p. 62).

Passou-se a utilizar o termo "femicídio" ou "feminicídio" para designar mortes de mulheres por razões associadas com seu gênero. Na América Latina, os referidos termos passaram a ser utilizados pelos movimentos feministas com o fim político de denunciar a violência contra as mulheres e a impunidade dos agressores (BORGES; GEBRIM, 2014). Os termos "femicídio" e "feminicídio" apesar de serem utilizados indistintamente na América Latina, referem-se aos assassinatos sexuais de mulheres, e portanto se diferenciam do homicídio. Entretanto é válido notar que,

algumas correntes sustentam que o termo "femicídio" não dá conta da complexidade nem da gravidade dos delitos contra a vida das mulheres por sua condição de gênero, pois etimologicamente significa unicamente dar morte a uma mulher. A expressão "feminicídio", por sua vez, englobaria a motivação baseada no gênero ou misoginia, agregando a inação estatal frente aos crimes (PATH apud BORGES; GEBRIM, 2014, p. 62).

O feminicídio não é apenas uma violência exercida por homens contra mulheres, mas por homens em posição de supremacia social, sexual, jurídica, econômica, política, ideológica... Sobre mulheres em condição de desigualdade, de subordinação, de exploração ou de opressão.

Vale ressaltar a existência de uma divergência sobre essa terminologia, por exemplo, nas palavras de Izabel Solyszko Gomes, o termo femicide foi traduzido como feminicídio em alguns países e como femicídio em outros, todos da América Latina. Alguns autores a exemplo da própria Izabel Solysko Gomes não concordam com tal diferenciação.

O observatório de Criminalidade do Ministério Público do Peru traz uma distinção relevante. Distinguindo o feminicídio em dois tipos: o íntimo, que é aquele em que a vítima tinha ou havia tido uma relação de casal com o homicida, não se limitando às relações com vínculo matrimonial, mas estendendo-se aos conviventes, noivos, namorados e parceiros, além daqueles praticados por um membro da família, como pai padrasto, irmão ou primo; e feminicídio 
não íntimo, aquele em que a vítima não tinha qualquer relação de casal ou familiar com o homicida (BORGES; GEBRIM, 2014).

Por sua vez o Observatório Cidadão Nacional de Feminicídio do México, indica as seguintes tipologias: feminicídio familiar íntimo, feminicídio familiar íntimo infantil, feminicídio infantil, feminicídio íntimo, feminicídio por roubo, feminicídio circunstancial, feminicídio por violência juvenil, feminicídio por vingança, feminicídio por orientação sexual, feminicídio por ocupação estigmatizada, feminicídio relacionado com o narcotráfico e feminicial sexual sistêmico (BORGES; GEBRIM, 2014).

Destaque-se que o feminicídio decorre de condições socioculturais, históricas, que geram e permitem práticas atentatórias contra a vida, a saúde, a integridade, a dignidade e a liberdade da mulher, com contribuição do Estado, por meio de sua ineficiência, negligência na prevenção, deficiência na investigação, ausência de repressão e de um quadro legal e político de governo, que favoreça a visibilidade da violência contra as mulheres e o fim da impunidade, do silêncio e da indiferença social.

\section{O Caso das mulheres da Ciudad JuARez (CAMpo Algodonero)}

Localizada no México na fronteira com os Estados Unidos a cidade de Juarez experimentou um grande aumento da industrialização e, consequentemente de fluxo migratório para ocupar as várias vagas de trabalho oferecidas pelas recém-chegadas indústrias. Ocupados estes em sua maioria por mulheres. Vários trabalhos e pesquisas já foram realizados na região onde se apontou as péssimas condições de trabalho nestas empresas. Já outras pesquisas apontaram a região como área de intensos conflitos entre traficantes de drogas e entre traficantes de drogas e as forças estatais.

No início da década de 1990 começou a avolumar denúncias sobre centenas de corpos de mulheres mutilados encontrados em meio ao lixo no deserto. Posteriormente descobriu-se que as referidas mortes estavam ligadas a violência de gênero. Entendido aqui como violência contra a mulher apenas pelo fato de ser mulher.

De início o discurso oficial das autoridades mexicanas era de que as mesmas tinham 'comportamentos duvidosos' 
e se encontravam, pouco antes de desaparecerem ou serem mortas, em situações comprometedoras em relação à moral familiar local: estavam em bares, festas, encontros amorosos furtivos ou circulando pelas ruas da cidade em horários "inadequados" (PASSOS, 2015, p. 74).

Quando as mulheres desapareciam os familiares das vítimas não obtinham nenhuma resposta do Estado. Tampouco quando algum corpo era encontrado não havia perspectiva de que iria ser realizada alguma diligência no sentido de elucidar os crimes. Aline PASSOS (2015, p. 75) destaca que,

Enquanto o Estado investia no discurso de moralização do comportamento das mulheres, movimentos sociais como a Coordenação de Organizações Não Governamentais em Defesa da Mulher e as Mulheres de Preto, formadas por familiares de vítimas e feministas em geral, contra-atacaram as instituições oficiais afirmando que as mulheres mortas não eram "públicas", mas trabalhadoras que se arriscavam a trabalhar fora de casa para ajudar financeiramente suas famílias.

A partir dessa estratégia os familiares das vítimas conseguiram notoriedade e mobilizaram as forças estatais para o problema das mortes de Juarez. Conseguiram inclusive atrair a atenção da política nacional e das Nações Unidas que designou uma investigação para desvendar os referidos crimes e da Anistia Internacional que produziu documento sobre a incompetência do governo mexicano em relação às mortes em Juarez. A partir dessas intervenções, tratou-se de demandar a responsabilidade pelos feminicídios em Juarez ao Estado pois, a impunidade construiu uma imagem de conivência com os feminicídios.

Pelas mortes em Juarez o Estado mexicano foi julgado na Corte Interamericana de Direitos Humanos onde admitiu responsabilidade parcial pelo que reconhecia como sendo um feminicídio em Juarez. Além do reconhecimento de um fenômeno chamado feminicídio, outro ponto a se destacar é o fato da violência ocorrer, sobretudo em ambiente familiar. Constituindo um verdadeiro paradoxo, nas palavras de Aline PASSOS (2015, p. 77),

ao mesmo tempo em que o Estado deve controlar e punir o feminicídio para a proteção da família, é sobre esta que recaem quase todas as acusações de produção dessas mortes, e é a elas que deve se endereçar a punição. Neste sentido, a chamada violência de gênero, que estaria no cerne da explicação causal do feminicídio, emerge não apenas como uma estratégia discursiva de defesa dos movimentos sociais, mas como um discurso de Estado que fixa a família como local privilegiado de novos investimentos de controle em nome do combate à violência contra a mulher. 
O Estado mexicano não cumpria o papel de dar satisfações aos familiares das vítimas dos crimes. A resposta imediata das organizações de defesa e proteção à mulher foi de que as mulheres vítimas de crimes não eram mulheres com hábitos duvidosos assim como afirmado pelas autoridades mexicanas. $\mathrm{E}$ sim, na verdade difundiram o discurso de que as vítimas eram mulheres de família, trabalhadoras, operárias, ou seja, mulheres honestas que não mereciam o descuido por parte do Estado e que o mesmo deveria agir para a proteção da família enquanto instituição.

Por isso enquanto o Estado difundia o discurso da mulher honesta e de bons costumes, de outra parte as organizações de proteção à mulher tiveram que aderir tal discurso para conseguir alguma resposta do Estado. Contribuindo assim para a construção da dualidade mulher honesta, casta e pura contra a mulher de moral duvidosa (puta entre outros). De outra parte não foi feito nada em relação à construção de um discurso inibidor da violência contra a mulher, seja ela quem for, na verdade,

quase nada, no entanto, pode ser dito sobre a emergência de novos costumes, escapes da moral familiar local ou deslocamentos das práticas sexuais, a partir do momento em que os movimentos sociais assumem um discurso que qualifica essas mulheres como moças de família, cuja principal característica, real ou imaginária, reside na obediência que não produz irrupções de práticas dissonantes da moral vigente. (PASSOS, 2015, p. 78).

A primeira vez que a palavra feminicídio foi usada nos tribunais americanos foi no caso de Campo Algodonero (González y otras vs. México). O referido caso serviu de base para traçar o que vem a ser feminicídio. No decorrer do processo chegaram-se à conclusão de que o maior número de agressões vinha de componentes da própria família. Contribuindo assim para configurar o feminicídio como crime que ocorre em maior número em ambiente familiar. Logo, feminicídio é caracterizado por matar mulher simplesmente por condição de ser mulher, num ambiente doméstico e/ou familiar. A própria Corte Interamericana de Direitos Humanos se pronunciou,

Os representantes disseram que "os homicídios e desaparecimentos de meninas e mulheres na Cidade de Juarez, são a máxima expressão da violência misógina”, razão pela qual alegaram que esta violência se conceitua como feminicídio. Segundo explicaram, ela consiste em "uma forma extrema de violência contra as mulheres; o assassinato de meninas e mulheres pelo único motivo de estarem em uma sociedade que as subordina”, o que tem implicação de "uma mistura de fatores culturais, econômicos e políticos". Por essa razão, 
argumentaram que "para determinar se um homicídio de uma mulher é um feminicídio é preciso conhecer quem o comete, como o faz e em que contexto". (...) De sua parte, o Estado, na audiência pública, utilizou a terminologia feminicídio ao fazer referência ao “fenômeno [...] que prevalece em Juarez (I/A COURT H.R., 2009, p. 41).

A partir do caso de Campo Algodonero podemos inferir que, feminicídio seria homicídio de mulher honesta, do lar, entre outros. E, a partir das reflexões trazidas pelo caso chegamos a uma universalização de direitos onde não só apenas a mulher honesta que não deve ser morta, mas na verdade nenhuma mulher, ainda mais nessas condições (de gênero) e em ambiente doméstico e familiar.

A pretensão que as partes levaram à Corte Interamericana de Direitos $\mathrm{Hu}$ manos foi a de que o Estado mexicano nem ao menos investigava as mortes contribuindo assim para a proliferação da cultura machista e misógina fazendo centenas de mulheres vítimas de violência letal. $O$ caso serviu para ajudar a delinear o que é um feminicídio assim como para a reflexão acerca de quem é o sujeito passivo desse tipo. Se mulheres honestas e do lar ou simplesmente mulheres. É interessante notar a contribuição do caso tanto para a configuração do feminicídio e assim maior proteção a mulher e coibição de violência contra a mesma, quanto para afastar qualquer condicional ou afastar a cobrança de alguma atitude por parte da mulher para poder ser o polo passivo de um crime de feminicídio.

\section{CONSIDERAÇÕES FINAIS}

Refletimos ao longo do presente trabalho a questão da violência contra mulher, um problema tão sério que a partir de 1950 já vem sendo debatido internacionalmente e, indiscutivelmente a violência contra a mulher deve ser contida. Tanto em relação à violência letal como da violência não letal.

A partir de dados estatísticos afirmamos que o Brasil é um país com altíssimo índice de violência contra a mulher, daí a urgente necessidade de tomar medidas institucionais práticas a fim de garantir os direitos humanos das mulheres (WAISELFISZ, 2015). Seguindo essa lógica podemos citar a própria lei Maria da Penha onde traz desde mudanças administrativas até passando por mudanças processuais penais e penais. Uma lei que, conforme sua própria ementa vem no interesse de garantir uma proteção merecida à mulher vítima 
de violência doméstica. E destacando uma importante lição que é a interpretação feita pelo Supremo Tribunal Federal na ADC 19/ADI 4424 (BRASIL, 2014). Reafirmando assim a constitucionalidade do uso de uma política afirmativa para garantir a concretização da norma constitucional.

Se antes da lei $n^{\circ} 13.104 / 2015$, ao se matar uma mulher, a critério do intérprete havia a possibilidade do réu ser condenado por homicídio qualificado por motivo torpe ou por motivo fútil. Contemporaneamente podemos pensar em avanço pois, existe uma legislação com o objetivo de penalizar quem ataca contra a vida de uma mulher por razões de gênero ou razões do sexo feminino,

A polêmica ainda residiria, pois, à luz da criminologia, quais os efeitos dessa tipificação? Ao se considerar que penas mais rigorosas não inibem o comportamento delituoso. Mais complicado ainda seria se afirmasse que, as penas nem ao menos ficaram significativamente mais rigorosas, quais os efeitos positivos da criminalização do assassinato de mulheres?

É tendência na América Latina e no mundo a adoção de medidas que visem assegurar os direitos humanos das mulheres. $\mathrm{O}$ próprio legislador pátrio nos informou de forma ímpar na ementa da lei Maria da Penha, as fontes das normas de proteção dos direitos humanos das mulheres no plano internacional. E, sabemos que é função do Estado buscar a concretividade dessa proteção pois, conforme os fundamentos insculpidos na Carta Maior o Estado brasileiro deve garantir o direito a uma vida digna a todos os cidadãos.

Percebemos que a lei do feminicídio, veio apenas no sentido criminalizador. Não traz nenhuma linha sequer versando sobre políticas que orientem a defesa da mulher e nem política criminal para a inibição da conduta pelos agressores. A norma se mostra apenas uma face, a encarceradora. Ao mesmo tempo em que não podemos nos esquivar de seu valor simbólico, devemos sempre lembrar a verdadeira função do direito penal que não tem sequer uma função preventiva. Ora, um novo tipo penal não inibe delitos.

Lembremos que enfrentar a violência contra a mulher não é coisa que se faça apenas com esforços legais. As soluções devem ser voltadas para a diminuição da desigualdade e da exclusão. Depende da formação de uma consciência crítica e de uma autocrítica das relações de poder, do patriarcalismo, e principalmente pelo diálogo de toda a sociedade. 


\section{REFERÊNCIAS BIBLIOGRÁFICAS}

ALVES, José Augusto Lindgren; Relações Internacionais e Temas Sociais - A Década das Conferências, item n. 7.6, 2001, Fundação Alexandre de Gusmão, Brasília.

ANDRADE, V. R. P. de. Sistema penal máximo x Cidadania mínima: códigos de violência na Era da globalização. Porto Alegre: Editora Livraria do Advogado, 2003.

BIANCHINI, Alice. Lei Maria da Penha: Lei 11.340/2006. Aspectos Assistenciais, Protetivos e Criminais da violência de gênero. 2. Ed. São Paulo. Saraiva. 2014.

BIANCHINI, A.; MARINELA, F; MEDEIROS, P. P. de. Feminicídio: o que não tem nome, não existe. 2015. Disponível em: <https://professoraalice.jusbrasil.com.br/artigos/171813462/feminicidio-o-que-nao-tem-nome-nao-existe $>$. Acesso em: 17/01/18. BORGES, Paulo Cézar Corrêa. ; GEBRIM, Luciana Maibashi. Violência de gênero: tipificar ou não o femicídio/feminicídio?. Id/503048, 2014. <http://www2.senado.leg. br/bdsf/bitstream/handle/id/503037/001011302.pdf?sequen>. Acesso em: 17/01/18.

BRASIL, Lei no 11.340 de 7 de agosto de 2006. Cria mecanismos para coibir a violência doméstica e familiar contra a mulher, nos termos do $\$ 8^{\circ}$ do art. 226 da Constituição Federal, da Convenção sobre a Eliminação de Todas as Formas de Discriminação contra as Mulheres e da Convenção Interamericana para Prevenir, Punir e Erradicar a Violência contra a Mulher; dispõe sobre a criação dos Juizados de Violência Doméstica e Familiar contra a Mulher; altera o Código de Processo Penal, o Código Penal e a Lei de Execução Penal; e dá outras providências. Disponível em: <http://www.planalto.gov.br/ccivil_03/_ato2004-2006/2006/lei/111340.htm>. Acesso em: 17/01/18.

BRASIL, Supremo Tribunal Federal. Acórdão na Ação Direta de Constitucionalidade n. 19/DF, Relator: MELLO, Marco Aurélio Mendes de Farias. Publicado no DJ de 29/04/2014. Disponível em: <http://www.stf.jus.br/portal/processo/verProcessoPeca. asp? $\mathrm{id}=217154893 \&$ tipoApp=.pdf $>$ Acessado em: 17/01/18.

COSTA, Marli. M.; NUNES, Josiane. B. A.; AQUINO, Quelen. B. Direito, Políticas Públicas e Gênero. Curitiba. MULTIDEIA. 2012.

DIAS, Maria Berenice. A lei Maria da Penha na Justiça: A efetividade da Lei 11.340/2006 de combate à violência doméstica e familiar contra a mulher. São Paulo. Revista dos Tribunais. 2007.

GOMES, Izabel Solyszko. Feminicídios e possíveis respostas penais: dialogando com o feminismo e o direito penal. Revista Gênero \& Direito, n. 1, 2015. <http://www.ies. ufpb.br/ojs2/index.php/ged/article/view/24472. Acesso em: 17/01/18 .

HERMANN, L. M. Maria da Penha: Lei com nome de mulher. Campinas: Editora Servanda. 2008.

HOBSBAWN, E. Era dos extremos: O breve século XX: 1914 - 1991. São Paulo: Companhia das Letras. 2001. 
I/A COURT H.R. (2009). Case of González et al. (“Cotton Field") v. Mexico. Preliminary Objection, Merits, Reparations and Costs. Judgment of November 16, 2009. Series C No. 205. Disponível em: $<$ http://www.corteidh.or.cr/docs/casos/articulos/seriec_205_ por.pdf $>$. Último acesso em 15/01/2018.

MOREIRA, Raquel Veggi; DE SOUZA, Carlos Henrique Medeiros; DE SOUZA, Luciano Dias. Uma reflexão sobre a participação da mulher na sociedade e a aplicação da Lei ${ }^{\circ}$ 11.340/2006 (Lei Maria da Penha) no contexto da violência. Revista Internacional de Investigación en Ciencias Sociales, v. 11, n. 2, p. 259-272, 2015. Disponível em: <http:// scielo.iics.una.py/pdf/riics/v11n2/v11n2a08.pdf >. Acesso em: 17/01/2018.

MURARO, Rose Marie. Breve Introdução Histórica. Disponível em: <www.dhnet.org. $\mathrm{br} /$ dados/livros/memoria/mundo/feiticeira/introducao.html $>$ Último acesso em 17/01/2018.

OCÁRIZ, Graziele Carra Dias. Feminicídio e a assistência às vítimas diretas e indiretas pela Defensoria Pública. Disponível em: <https://www.anadep.org.br/wtksite/ cms/conteudo/25712/GRAZIELE_CARRA_DIAS_OC_RIZ.pdf> Último acesso em $17 / 01 / 2018$.

PASSOS, Aline. O feminicídio nas fronteiras da América Latina: um consenso?. Revista Ecopolítica, São Paulo, n. 12, mai-ago, pp. 70-92. 2015.

PORTO, Pedro Rui da Fontoura. Violência Doméstica e Familiar Contra a Mulher: Lei

11.340/06 análise crítica e sistêmica. Porto Alegre. Livraria do Advogado. 2007.

WAISELFISZ, J. J. Mapa da violência 2015: Homicídios de mulheres no Brasil. Brasília: Disponível em: <http://www.mapadaviolencia.org.br/>. Último acesso em: 17/01/2018. 